\title{
Expected Inflation Near and Far
}

\author{
David C. Wheelock
}

$\mathbf{F}$

luctuations in the price of oil and other apparently nonmonetary phenomena often seem to drive the near-term outlook for inflation. Nonetheless, economists widely accept the view that, over the long run, inflation is determined by monetary policy. Thus, at longer horizons, expected inflation primarily reflects the public's view of the monetary policymaker's inflation objective. Put another way, fluctuations in oil prices and other nonmonetary phenomena will have less impact on the public's longrun inflation forecasts the more strongly the public sees policymakers as being committed to a particular inflation objective.

To gauge inflation expectations, analysts typically look to either surveys or market measures, such as the difference in yields on ordinary Treasury securities and inflation-protected Treasury securities (TIPS) of similar maturity. An increase in the yields on ordinary securities relative to those on TIPS would suggest that market participants have raised their forecast for inflation over the life of the securities. ${ }^{1}$

The chart plots monthly observations on the 5-year TIPS spread from January 2004 through November 2006. The spread fluctuated widely in 2004 and 2005, reflecting both volatility in oil prices and uncertainty about the economic outlook following hurricanes Katrina and Rita. More recent changes in the spread have also closely coincided with fluctuations in energy prices. A sharp decline in the spread in the second half of 2006, for example, coincided with a large decline in the price of oil from over $\$ 74$ per barrel in July to less than $\$ 60$ per barrel in October.

Although measures of near-term expected inflation, such as the 5-year TIPS spread, have moved closely with energy prices, measures of expected inflation over longer horizons have been less sensitive to fluctuations in energy prices. For example, the 5-year forward TIPS spread, which reflects expected inflation over the 5-year period beginning 5 years in the future, has been less closely correlated with fluctuations in oil prices than the TIPS spread covering the current 5-year period. ${ }^{2}$ The 5 -year forward TIPS spread, which is also shown in the chart, has ranged between 2.25 and 2.75 percent since 2004 and declined only modestly with the fall in oil prices in the second half of 2006. Survey measures of expected inflation over long horizons, such as the Survey of Professional Forecasters by the Federal Reserve Bank of Philadelphia, have been even more stable. The median 10-year average CPI inflation forecast from the Survey of Professional Forecasters has been within 0.10 percentage points of 2.5 percent since $1999 .{ }^{3}$

The relative stability of measures of expected inflation over longer horizons indicates that market participants view the impact of fluctuations in oil prices on inflation as largely transitory. Appar ently, the public has remained convinced that the Federal Reserve is committed to keeping inflation low. If measures of long-term expected inflation were to rise significantly, it would reflect less about the price of oil than it would about the credibility of the Federal Reserve's commitment to holding inflation in check.

\footnotetext{
${ }^{1}$ An increase could also reflect an increase in inflation-risk premiums. For a discussion of the use of the TIPS yield spread as a measure of expected inflation, see Kevin L. Kliesen and Frank A. Schmid, "Monetary Policy Actions, Macroeconomic Data Releases, and Inflation Expectations," Federal Reserve Bank of St. Louis Review, May/June 2004, 86(3), pp. 9-21.

2 The 5 -year forward TIPS spread is obtained by dividing the total inflation expected over the entire 10 years $\left[(1+10 \text {-Yr TIPS Spread })^{10}\right]$ by the total inflation expected over the first 5 years $\left[(1+5 \text {-Yr TIPS Spread })^{5}\right]$ and then taking this ratio's 5 th root (equivalent to raising it to the 0.2 power) to get the average annual rate. ${ }^{3}$ See www.philadelphiafed.org/econ/spf/index.html.
}

TIPS Spreads and the Price of Oil

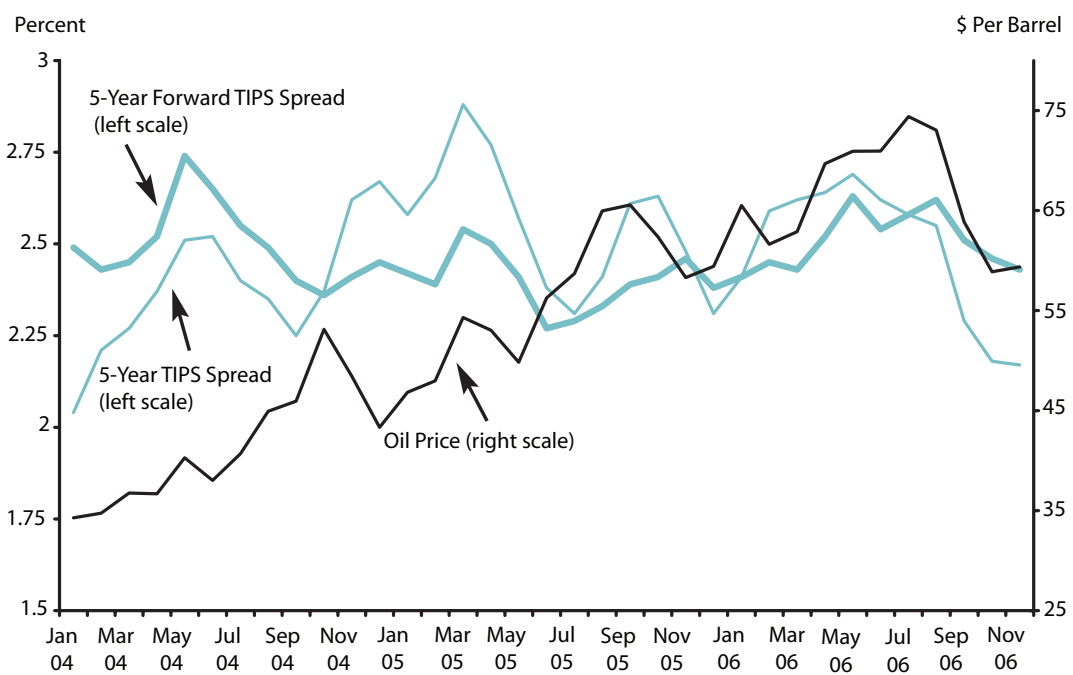

Views expressed do not necessarily reflect official positions of the Federal Reserve System. 